\title{
In vitro studies of 3-O-Methylquercetin against phytopathogenic fungi of major cereals
}

\section{Catherine Kitonde ${ }^{1 *}$, Saifuddin Fidahusein Dossaji ${ }^{1}$, Catherine Wanjiru Lukhoba ${ }^{1}$, John Maina Wagacha1, Carla Klittich², Donald Hahn², Serge Fotso ${ }^{2}$, Paul Graupner ${ }^{2}$, Thomas Slanec ${ }^{2}$ and Quanbo Xiong'}

\author{
${ }^{1}$ School of Biological Sciences, University of Nairobi (UoN). Riverside Drive, Off Chiromo Road. P.O. Box 30197-00100. \\ Nairobi-Kenya. \\ ${ }^{2}$ Crop Protection Discovery, Corteva Agriscience. 9330 Zionsville Road. Indianapolis, IN 46268 United States.
}

*Corresponding author. Email: ckitonde@uonbi.ac.ke

Copyright (@ 2019 Kitonde et al. This article remains permanently open access under the terms of the Creative Commons Attribution License 4.0, which permits unrestricted use, distribution, and reproduction in any medium, provided the original work is properly cited.

Received 11th May, 2019; Accepted 3rd July, 2019

\begin{abstract}
Maize, wheat, and rice are major cereal crops in the world, which provide more caloric energy than any other type of cereal class. In recent years, the yield of these cereal grains has stagnated due to a myriad of constraints, including infestation by pests and pathogens. Plant pathogens, especially agricultural phytopathogenic fungi, may be resistant to the available chemical fungicides which may have detrimental effects and are expensive. This study investigated whether natural products isolated from Linzia glabra Steetz of family Asteraceae could be used as alternative antifungals for control of cereal diseases caused by agricultural fungi. A single pure fraction was separated and identified from L. glabra methanolic flower crude extract using high performance liquid chromatography and high resolution mass spectrometry methods. The pure fraction isolated was tested for inhibition of spore germination in vitro against Fusarium graminearum, Fusarium oxysporum, Fusarium verticillioides, Zymoseptoria tritici, Ustilago maydis, and Pyricularia oryzae. The fraction was identified as a flavonol, 3-O-Methylquercetin using high resolution mass spectrometry. Among the fungi tested, spores of $Z$. tritici were the most susceptible to 3 -O-Methylquercetin (44\% spore inhibition), followed by $F$. oxysporum (33\% inhibition) at $27 \mu \mathrm{g} / \mathrm{mL}$. Azoxystrobin, a standard commercialized fungicide, gave a complete inhibition of $100 \%$ against $Z$. tritici and $58 \%$ inhibition against $F$. oxysporum at $5 \mu \mathrm{g} / \mathrm{mL}$. L. glabra contains flavonols with antifungal activity, but the modest and weak antifungal activity of 3-O-Methylquercetin compared to a standard such as azoxystrobin demonstrates the challenge to produce highly potent natural product fungicides. There is need for continued search for antifungals with new modes of action as solutions to challenges in agricultural production.
\end{abstract}

Keywords: Alternative antifungals, cereal crops, flavonoid concentration, flavonols, plant diseases, Linzia glabra Steetz.

\section{INTRODUCTION}

Cereal crops are monocotyledons of the grass family Poaceae, grown for their edible starchy seeds (Ji et al., 2013). According to Ranum et al. (2014), cereal grains have provided humankind with more nourishment than any other food class. The three major cereal crops in the world, namely maize (Zea mays), wheat (Triticum sp.), and rice (Oryza sativa) (Ji et al., 2013; Awika, 2011), provide two thirds of the world's food energy intake (Ji et al., 2013).
Developing countries depend more on cereal grains for their nutritional needs than the developed world with close to $60 \%$ of calories derived directly from cereals and accounting for $80 \%$ calories in the poorest countries (Awika, 2011).

Although crop yields have improved tremendously in the past 50 years due to technological advances, plant diseases and pests, population increase and climate 
change continue to threaten the sustainability of current cereal production (Ji et al., 2013). In addition, the grain quality is reduced due to pest infestation and contamination of the grains with mycotoxins in the field, leading to significant losses to farmers (Kibet, 2011).

Plant diseases that infect maize, wheat, and rice crops are of fungal, bacterial, and viral pathogens, but fungi are main disease causing organisms of plants, leading to approximately 40 to $60 \%$ yield losses of world agricultural production (Owen et al., 2017). Maize, wheat and rice crops are attacked by seedling and head blights, root rot, stalk rot, ear rots, kernel rots, vascular wilts, leaf spots, blotches, and rusts, the majority of which are considered economically significant diseases (Hafiz, 1986). According to Ramsey (2012), the major economically significant fungal pathogens causing devastating diseases to maize, wheat and rice are Zymoseptoria tritici (Desmazieres) Quaedvlieg and Crous, Ustilago maydis (de Candolle) Corda, Pyricularia oryzae Briosi \& Cavara and Fusarium species (Stenglein, 2009).

$Z$. tritici is a foliar fungal pathogen causing blotch disease of wheat leaves, and it may cause complete leaf death when the blotches are severe (Hollaway, 2014), leading to yield losses of 30 to $50 \%$ (Solomon, 2017). U. maydis causes common smut disease in maize/or corn, infecting tassels, ear tips, stalks and leaves (Infornetbiovision, 2011). The yield losses by common smut disease may be significant ranging up to $10 \%$ (Pataky and Snetselaar, 2006). P. oryzae causes blast disease of rice, which is a destructive disease causing yield losses of 60 to $100 \%$ (Kihoro et al., 2013).

Although chemical fungicides have been the preferred first used method for management of some agricultural fungal diseases, they may have undesirable effects on human and animal health, prompt environmental hazards, select resistant lines and are usually expensive for the poor farmers (Peter, 2002). Therefore, there is need for providing alternative methods for managing the phytopathogenic fungi such as natural products from pesticidal plants that might be cheaper and low in toxicity.

Linzia glabra Steetz (Hassler, 2019) (formerly Vernonia glabra (Steetz) Oliv. \& Hiern, is a species inhabiting roadsides, grassland and riverine vegetation and grows in altitude ranging from 980 to $1640 \mathrm{~m}$. It is widely distributed in the African region, occurring in Botswana, D.R Congo, Kenya, Malawi, Mozambique, South Africa, Zambia, Zimbabwe, and Tanzania (Herman and Swelankomo, 2011). In Kenya, the plant occurs naturally, usually as a pioneer in disturbed grassland, shallow and impermeable soils (Agnew and Agnew, 1994).

L. glabra was selected for this study based on ethnomedicinal information from literature. Johns et al. (1995) reported that a decoction of leaf plus root administered orally treats gastrointestinal problems in Kenya. According to Owuor and Kisangau (2006), the leaf ash or crushed leaves rubbed into scarification around a snake bite acts as an antidote (cure or remedy) in Kenya. Kitonde et al. (2013) reported antibacterial and antifungal activities of the crude extracts of the flowers, leaves, stem, and roots of $L$. glabra, against human pathogens, namely: gram positive bacterium-Staphylococcus aureus, gram negative bacterium-Escherichia coli, filamentous fungusAspergilus niger, and yeast fungus-Candida albicans. Studies by Johns et al. (1995) have also reported activity against Giardia lamblia, a flagellated parasitic protozoan. Presence of flavonoids, alkaloids, sapongenins, terpenoids, and quinones have been reported in leaves, flowers, stem, and root crude extracts of $L$. glabra (Kitonde et al., 2013). However, no research have been conducted on agricultural plant health using L. glabra extracts, and thus this plant was selected to investigate its suitability as an alternative method in the management of economically important agricultural phytopathogenic fungi, $Z$. tritici, $U$. maydis, P.oryzae, F. graminearum, Schwabe (teleomorph: Gibberella zeae (Schwein.) Petch), F. oxysporum f.sp. cubense (E.F.Sm.) W.C.Snyder \& H.N. Hansen, and F. verticillioides (Saccardo) Nirenberg that cause yield losses worldwide.

Plants produce a wide variety of secondary metabolites that help them withstand attacks from fungi, bacteria, viruses, and ultraviolet radiation (Chadwick et al., 2013). These compounds are often terpenoids, phenolics and alkaloids (Chadwick et al., 2013). According to Jaisankar et al. (2014), flavonoids are low molecular weight polyphenolic compounds with a three-ring structure substituted as hydroxylation, methoxylation, glycosylation, or prenylation and are responsible for the vibrant colours of many plants. Flavonols, flavones, flavanols, flavanones, isoflavones, anthocyanidins and chalcones are the most common subclasses of flavonoids accounting for approximately $80 \%$ of total flavonoids identified (Jaisankar et al., 2014). In plants, flavonoids are responsible for various biological processes including seed development and growth (Song et al., 2016), fruit growth and ripening (Andreotti et al., 2008), hormone transport (Peer and Murphy, 2007) and pollen tube germination (Ylstra et al., 1992). Flavonoids respond to biotic and abiotic dynamics by providing antioxidant activity that reduces damage caused by fungi, bacteria, viruses, and herbivores, act as chemical attractants to pollinating organisms and chemical messengers in association with mycorrhizae and bacteria, and have allelopathic functions (Wink, 2010; Agati et al., 2012).

Flavonoids are also reported to have been used in human health for prevention and treatment of cardiovascular diseases, diabetes, cancer, chronic inflammatory disorders, and degenerative diseases (Ghasemzadeh and Ghasemzadeh, 2011), as well as lowering blood cholesterol (Rivera et al., 2010).

Flavonols are a class of flavonoids that mainly accumulate in the epidermal cells of plant tissues especially in the aerial parts (flowers), leaves, and fruits 
since their biosynthesis is stimulated in response to solar radiation, filtering radiation that could damage DNA (Kolb et al., 2001). They are generally present in relatively low concentrations (Tazzini, 2014). Chemically, flavonols differ from many other flavonoids in their double bond between carbon positions 2 and 3 and an oxygen (a ketone group) in the carbon position 4 of the $C$ ring, while flavones differ in the absence of a hydroxyl group at carbon position 3 (Tazzini, 2014).

Some flavonols are linked with sugar moieties (glycoside derivatives) such as glucose or rhamnose, for instance, Quercetin and Kaempferol flavonols (Jaisankar et al., 2014; Hollman and Arts, 2000). Other sugar moieties may also be involved such as galactose, arabinose, xylose and glucuronic acid, while other flavonols occur as free forms, aglycones (without sugar), (Hollman and Arts, 2000). The sugar moiety influences flavonol bioavailability and absorption in biological systems (Hollman and Arts, 2000).

Flavonols are reported to possess antioxidant properties that prevent plant cells from photo-oxidative damage by countering increases in concentration of reactive oxygen species, which happens by inhibition of the enzymes involved in reactive oxygen species generation (Justyna et al., 2014) and regulating the development of individual organs and the whole plant (Pollastri and Tattini, 2011). Antibacterial activity has been reported on 3-OMethylquercetin and 3,3'-di-O-Methylquercetin against Salmonelle typhimurium and Bacillus cereus at $125 \mu \mathrm{g} / \mathrm{mL}$, whereby 3, 3'-di-O-Methylquercetin mechanism of action was reported to induce damage in bacterial cell walls and cytoplasmic membrane (Wamidh et al., 2012). There is no report on the mechanism of action on fungi. Quercetin, rutin, and naringin are some of the flavonols reported to have shown positive effects in the control of insect pests such as nymphs and adults of the aphid Eriosoma lanigerum Hausmann, and therefore, they are recommended for use as insecticides for this aphid (Palma-Tenango et al., 2017).

There is no published research on the study of the antifungal activity of the flavonol 3-O-Methylquercetin (which can be isolated from L. glabra Steetz a plant common in Kenya) against economically important agricultural fungal pathogens. This study investigated the in vitro effect of 3-O-Methylquercetin isolated from $L$. glabra against six economically important agricultural fungal pathogens ( $F$. graminearum, $F$. oxysporum, $F$. verticillioides, $Z$. tritici, $U$. maydis and $P$. oryzae).

\section{MATERIALS AND METHODS}

\section{Plant collection, drying and extraction}

The flowers of Linzia glabra were collected in January, 2013 from one site, Kathiani Sub-County of Machakos County in the lower Eastern Kenya, which falls within the floral region K4 (Figure 1), according to Flora of Tropical East Africa (FTEA) (Beentje, 1994). The flowers were put in five clean open khaki bags and allowed to dry in an aerated room for two weeks at room temperature (23 \pm $2^{\circ} \mathrm{C}$ ). A voucher specimen of the plant (CK 2013/01) was authenticated using keys, comparison with authentic herbarium materials and expert examination by a Plant Taxonomist at the University of Nairobi. The voucher specimen of the plant in flower was prepared using standard herbarium methods (Agnew and Agnew, 1994; Beentje, 1994), and deposited in the University of Nairobi Herbarium.

The dried L. glabra flowers were ground into powder using an electric grinder (KM-1500 Cutting mill, MRC Laboratory Equipment Manufacturer, Hagavish 3 Holon, Israel) and extracted using absolute methanol according to standard extraction methods (Harborne, 1998), with minor modification. Five hundred milliliters of absolute methanol (Fisher chemical, HPLC grade $99.99 \%$, New Jersey, USA) was mixed thoroughly with $40 \mathrm{~g}$ of flower powder and filtered every 24 hours for three days through cheese cloth (Ramos et al., 2006). The filtrates were pooled and filtered again using a Buchner funnel and sterile filter paper Whatman No 1 . The dry crude flower extract $(10 \mathrm{~g})$ was stored in a glass vial at $4^{\circ} \mathrm{C}$.

\section{Isolation and identification of pure compounds from $L$. glabra Steetz methanol crude flower extract}

Isolation and purification of the pure compounds was achieved by use of Reversed Phase High Performance Liquid Chromatography (RPHPLC) and Preparative High Performance Liquid Chromatography (PHPLC) on the methanolic crude extract from L. glabra Steetz flower. Four grams of crude flower extract of $L$. glabra Steetz was mixed with $10 \mathrm{~g}$ Celite (TM; 545 Filter Aid-Fisher chemical) absolute Methanol (Fisher chemical, HPLC grade 99.99\%, New Jersey, USA) and evaporated to dryness using a rotary evaporator under vacuum (BÜCHI model RE114, Germany) at $40^{\circ} \mathrm{C}$. The obtained powder was loaded in a 25 g cartridge (Redi $\operatorname{Sep}^{R} R f$ ) and separated on a HPLC CombiFlash $^{\circledR} R F$ system (Agilent Technologies 1200 series, USA) using Dichloromethane (Fisher chemical, HPLC grade $99.99 \%$, New Jersey, USA) and Methanol (Fisher chemical, HPLC grade 99.99\%, New Jersey, USA). Eight fractions were obtained and $5 \mathrm{mg}$ of each fraction were weighed and subjected to in vitro bioassay. The active fractions were purified using preparative high performance liquid chromatography (PHPLC- Agilent Technologies 1200 series, CA, USA) to afford the active compound. Preparative HPLC was conducted on a Phenomenex Luna C8 column ( $250 \times 21.20 \mathrm{~mm}, 5 \mu \mathrm{m})$, eluted with gradient solvent $A=0.1 \%$ formic acid $(88 \%$ Assay grade, Fisher Chemical, USA) in water and $B=$ acetonitrile (HPLC Grade 99.99\%, Fisher Chemical, USA) (buffer) solvent. 


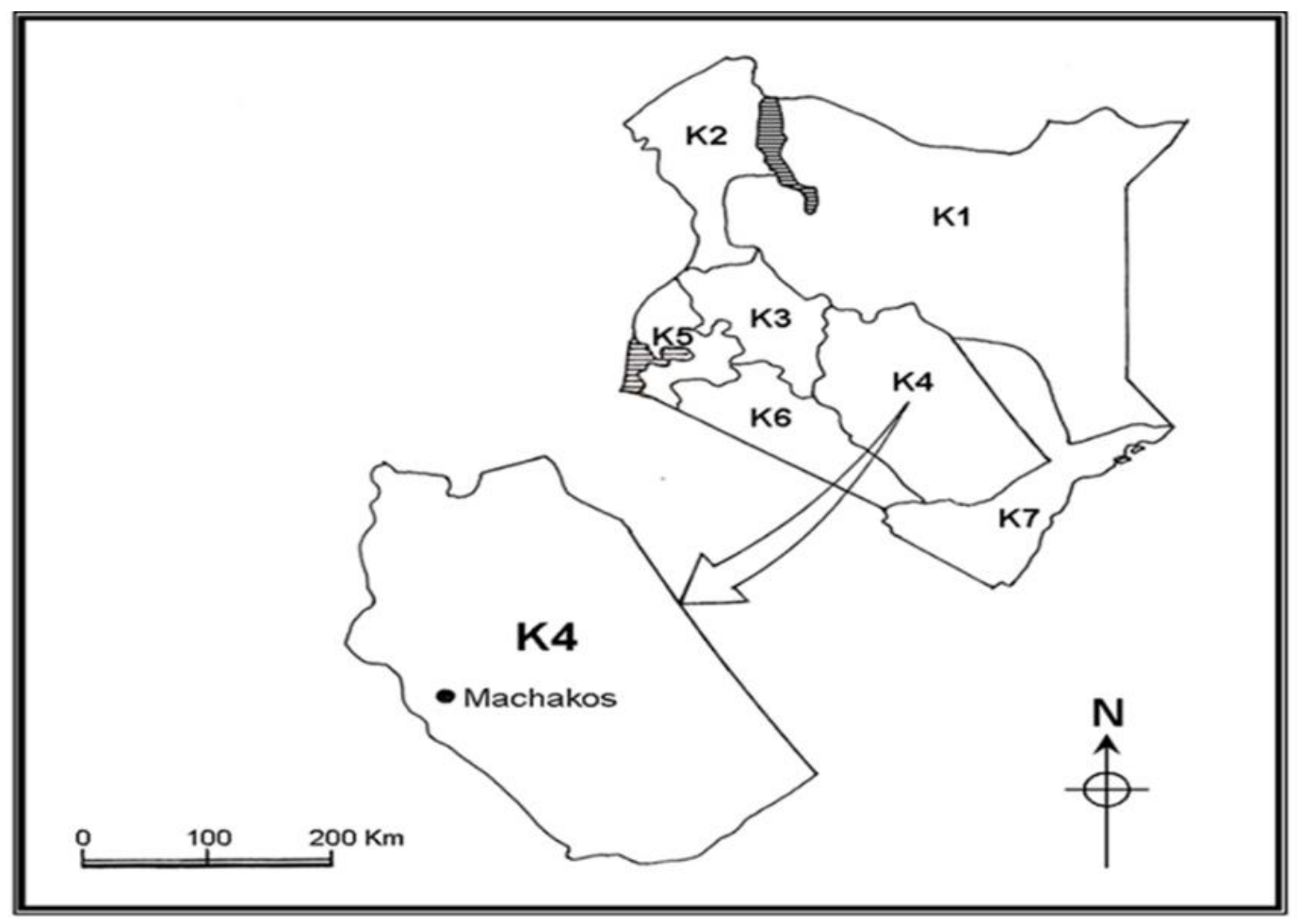

Figure 1. A map of Kenya showing floral regions (Top right) and plant collection site Kathiani in Machakos County (K4 bottom left). K1-K7 stands for Floral Regions of Kenya according to Flora of Tropical East Africa (FTEA) (Beentje, (1994) (Top Right); and plant collection site (Bottom Left).

\section{High performance Liquid Chromatography/Time-of- mass spectrometry (HPLC/TOF-MS)}

The LC/TOF-MS system consisted of Agilent 1200 HPLC which was connected to a disarray detector (DAD), and a 6200 time of flight mass spectrometer (Agilent Technologies, Santa Clara, CA, USA), equipped with dual electrospray interface. The analysis was performed on Hypersil Gold column of $2.1 \mathrm{~mm}$ x $50 \mathrm{~mm}$ and $1.9 \mu \mathrm{m}$ particle size (Thermo Fisher Scientific Inc. ${ }^{\circledR}$, USA). Mobile phase A consisted of $5 \mathrm{Mm} \mathrm{NH4OAC} \mathrm{(Ammonium} \mathrm{acetate)}$ in water and B was acetonitrile (HPLC Grade 99.99\%, Fisher Chemica, USA). The chromatography was run at $0.4 \mathrm{~mL} / \mathrm{min}$ for 20 minutes, which held the initial mobile phase composition ( $5 \%$ B) constant for 1 minute, followed by a linear gradient to $100 \% \mathrm{~B}$ at 10 minutes, and stayed at $100 \% \mathrm{~B}$ for 5 minutes. The gradient was then immediately dropped to $0 \% \mathrm{~B}$ over 0.1 minute, and held to re-equilibrate for 5 minutes before the next injection. The following operation parameters were used in a positive mode of the TOF-MS analyzer: capillary voltage, $3200 \mathrm{~V}$; nebulizer pressure, $45 \mathrm{psi}$; drying gas flow rate, $11 \mathrm{~L} / \mathrm{min}$; gas temperature, $350^{\circ} \mathrm{C}$; skimmer voltage, $60 \mathrm{~V}$; octapole rf, $250 \mathrm{~V}$; fragmentor voltage, $150 \mathrm{~V}$. The molecular formula of the analyte was predicated using MassHunter software (Agilent) based on the accurate mass, isotope spacing and relative abundance of monoisotopes of the spectrum.

\section{Antifungal assay}

The fungal pathogens used for in vitro testing were Zymoseptoria tritici ATCC 26518, Ustilago maydis DAS strain, Pyricularia oryzae DAS strain 164, Fusarium graminearum strain 2-0369, $F$. oxysporum strain f.sp. lycopersici 0-1080 and F. verticillioides NRRL 22172 provided by Corteva agriscience. The antifungal activity of the isolated pure compound was compared to the commercial standard fungicide, azoxystrobin (Technical grade, ChemService, Inc., West Chester, PA, USA) (Bartlett et al., 2002).

The in vitro assay for inhibition of spore germination was conducted using 96-well microtiter plates as described by Owen et al. (2017). Eight two-fold serial dilutions of the pure compound $(27,13.5,6.75,3.37,1.68,0.84,0.42$, and $0.21 \mu \mathrm{g} / \mathrm{mL}$ ) were dispensed in four columns of microtiter plates $\times 3$ replicates. Eight similarly prepared dilutions of azoxystrobin $(5,2.5,1.25,0.625,0.3125,0.156,0.078$, and $0.039 \mu \mathrm{g} / \mathrm{mL}$ ) in four columns $\times 3$ replicates were also prepared using stock solutions in absolute Methanol (Fisher chemical, HPLC grade $99.99 \%$, New Jersey, USA). 
All dilutions were then dried to powder using a SpeedVac rotary under vacuum (Savant Explorer Thermo Electron Corporation Speedvac System; Indiana; USA). The dried powders from the serial dilutions of the pure compound and azoxystrobin were re-dissolved in $2 \mu \mathrm{L}$ aliquots of dimethyl sulfoxide (Fisher Chemical, 99.9\% Assay Grade, New Jersey, USA) in sterile distilled water (DMSO: $\left.\mathrm{H}_{2} \mathrm{O}=2: 8 \mathrm{v} / \mathrm{v}=1: 4\right)$. Three replicates of dimethyl sulfoxide in sterile distilled water were used as a negative control and dispensed in the remaining four columns of the microtiter plates.

The growth medium for in vitro antifungal assays consisted of $20 \mathrm{~g}$ glucose (Anhydrous, Fisher Chemical, USA), $3 \mathrm{~g}$ Dipotassium-Hydrogen Phosphate $\left(\mathrm{K}_{2} \mathrm{HPO}_{4}\right)$ (Assay grade, Fisher Chemical, USA), $3 \mathrm{~g}$ PotassiumDihydrogen Phosphate $\left(\mathrm{KH}_{2} \mathrm{PO}_{4}\right)$ (Assay grade, Fisher Chemical, USA) and $6.7 \mathrm{~g}$ of yeast Nitrogen base without amino acids (Difco Yeast Nitrogen Base W/O Amino Acids, Becton, Dickinson and Company, USA) added to 1 litre of de-ionized water and sterilized by autoclaving. Fungal inoculums were prepared by flooding mycelia grown on agar media plates with the above liquid medium to cover the entire surface of the culture, then lightly scraping the agar surface with a sterile plastic cell lifter to release the spores and conidia (Hodgson et al., 1964). Each fungal inoculum was filtered through a sterile $100 \mu \mathrm{M}$ nylon mesh filter cell strainer cap (Fisher brand, Thermo Fisher Scientific Inc ${ }^{\circledR}$ Waltham, Massachusetts, U.S.A) to remove any mycelia debris (Owen et al., 2015). Initial inoculum densities were adjusted according to Owen et al. (2017), with slight modifications. For Fusarium pathogens and $Z$. tritici tested, 100,000 spores $/ \mathrm{mL}\left(1.0 \times 10^{5}\right)$ were used, while 40,000 spores $/ \mathrm{mL}\left(4.0 \times 10^{4}\right)$ for $P$. oryzae and 50,000 spores $/ \mathrm{mL}\left(5.0 \times 10^{4}\right)$ for $U$. maydis.

Aliquots of $200 \mu \mathrm{L}$ of the standardized inoculum were dispensed into each microtiter plate well, using a Matrix well-mate multi-dispenser machine (Thermo Fisher Scientific, Massachusetts, USA). Plates were incubated in the dark for 48 hours at $24^{\circ} \mathrm{C}$ (U. maydis); 72 hours at $22^{\circ} \mathrm{C}$ $\left(P\right.$. oryzae and Z. tritici) or 72 hours at $25^{\circ} \mathrm{C}$ (Fusarium graminearum, $F$. verticillioides, and $F$. oxysporum) (Owen et al., 2017).

Initial and final fungal spore density readings were determined using a NepheloStar Nephelometer ${ }^{\circledR}$ (BMG Labtech GmbH, D-77799 Ortenberg Germany) (Owen et al., 2017). Assays were carried out in triplicate and percentage inhibition of spore germination was calculated by reference to control wells containing only growth medium amended with $2 \mu \mathrm{L}$ DMSO and inoculum, using the following formula by Owen et al. (2017) and Kumari et al. (2013).

$[i] \%$ inhibition of spore germination $=\left[\frac{N-(F A 1-I A 1)}{N}\right] \times 100$

Where: $F A_{1}=$ Final spore density reading in well $A_{1}$ inoculated with test-organism and treated with the test compound, $I A_{1}=$ Initial spore density reading in well $A_{1}$ inoculated with test-organism and treated with the test compound; $\mathrm{N}=$ Normal spore density in wells with growth medium and DMSO (99.9\% Assay Grade, Fisher Chemical, USA) only inoculated with test-organism.

\section{Data analysis}

Data were analyzed using $\mathrm{R}$ Guide program software version Rx64-bit 3.3.3, (released in 2012). The analyses included Analysis of Variance (ANOVA) to determine significant factors/or variables that influenced inhibition of spore germination and Tukey's Honest Significant Difference (THSD) test to determine which factors were significantly different in influencing the inhibition (Brown, 2012). Microsoft word 2010 was used to draw tables; Microsoft Excel 2010 was used to determine percentage mean inhibition of spore germination and plotting of bar graphs.

\section{RESULTS}

This research generated $42 \mathrm{mg}$ of a flavonol, 3-OMethylquercetin, a yellow amorhous powder, isolated for the first time from Linzia glabra. Chromatography of the compound on LC-TOF analysis gave a single peak at 7.8 min. The DAD showed UV maximal at 255 and $360 \mathrm{~nm}$; High resolution TOF MS gave the $[\mathrm{M}+\mathrm{H}]^{+}$at $\mathrm{m} / \mathrm{z} 317.0660$ suggesting a molecular formula to be $\mathrm{C}_{16} \mathrm{H}_{12} \mathrm{O}_{7}$ and exact mass $316.0587 \mathrm{Da}$, with $1.38 \mathrm{ppm}$ error. The molecule has a high double bond equivalent (DBE) of 11 (Figure 2). These data suggested a possible flavonol structure of 3$O$-Methyquercetin (Figure 3 ) that matches very well in the literature (Bouktaib et al., 2002).

\section{Antifungal activity of 3-O-Methylquercetin compared to Azoxystrobin}

The effect of 3-O-Methylquercetin on spore germination of $Z$. tritici, $U$. maydis, $P$. oryzae, Fusarium graminearum, $F$. oxysporum and $F$. verticillioides was different from that of the standard azoxystrobin with high significance at $p \leq 0.0001$ (Table 1). Dose rates (chemical concentrations) also had a significant effect on fungal inhibition at $p \leq 0.001$. Test organisms were significantly different from each other in their response to the compounds at $p \leq 0.0001$ (Table 1).

The inhibition of spore germination by $3-O-$ Methylquercetin at the highest concentration of $27 \mu \mathrm{g} / \mathrm{mL}$ compared to Azoxystrobin at $5 \mu \mathrm{g} / \mathrm{mL}$ ( $5 \mathrm{ppm}$ ), revealed that the former showed modest to low activity against the test organisms; $44 \%$ inhibition of spore germination against $Z$. tritici, $33 \%$ against $F$. oxysporum, $24 \%$ against both $P$. oryzaea and $F$. verticillioides, $23 \%$ against $F$. 


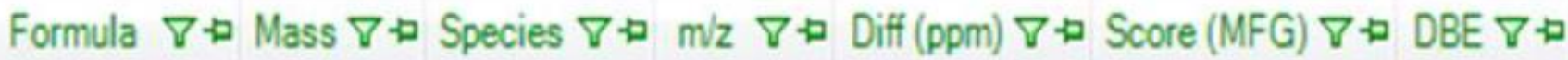 C16 H12 $07 \quad|316.0587|(M+H)+\quad|317.0660|-1.38 \quad \mid 99.42$}

Figure 2. Molecular formula of 3-O-Methylquercetin of ion $[\mathrm{M}+\mathrm{H}]^{+}$; exact mass $316.0587 \mathrm{Da}$, mass-to-charge ratio $(\mathrm{m} / \mathrm{z})$ 317.0660 , relative probability score of $99.42 \%$ and double bond equivalent (DBE) of 11 .

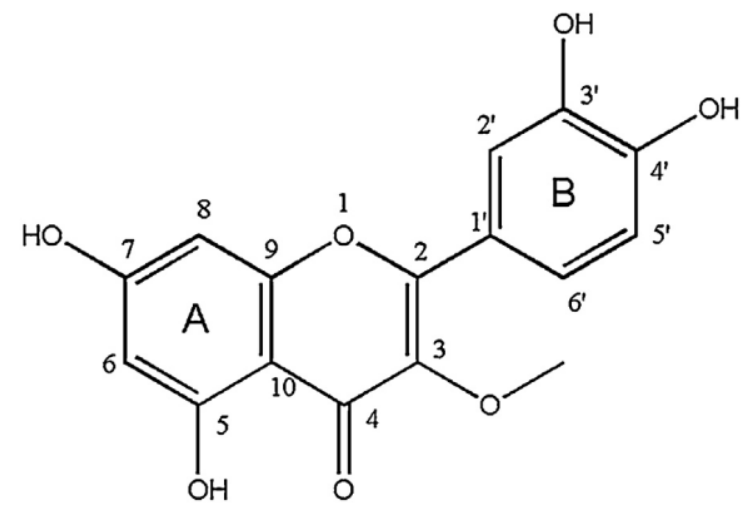

Figure 3. Molecular structure for 3-O-Methylquercetin isolated from Linzia glabra flower crude extract.

Table 1. Analysis of variance shows inhibition of spore germination was influenced by chemical class, chemical concentration, and test-organism at $\mathrm{p} \leq 0.05$.

\begin{tabular}{lccccc}
\hline Variables/factors & Df & Sum Sq & Mean Sq & F value & Pr $(>$ F) \\
\hline Chemical class & 2 & 80414 & 40207 & 209.004 & $<2 e-16^{* * *}$ \\
Chemical concentration & 14 & 7228 & 516 & 2.684 & $0.00187^{* *}$ \\
Test-organism & 5 & 14617 & 2436 & 12.664 & $4.72 \mathrm{e}-11^{* * *}$ \\
Residuals & 121 & 23277 & 192 & & \\
\hline
\end{tabular}

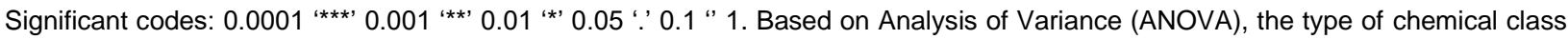
used, chemical concentration, and test-organism factors (variables) were significant at $p \leq 0.05$. DF=Degrees of freedom; Sum Sq=Sum of squares; Mean Sq=Mean sum of squares; $\operatorname{Pr}(>\mathrm{F})=\mathrm{P}$ value; DMSO-Dimethyl sulfoxide.

graminearum and $17 \%$ against $U$. maydis (Figure 4). Azoxystrobin, on the other hand, had a strong activity against $Z$. tritici $(100 \%)$ at $5 \mu \mathrm{g} / \mathrm{mL}$, while the negative control, dimethyl sulfoxide (DMSO), was inactive (Figure $4)$.

\section{Minimum inhibitory concentration of 3-O- Methylquercetin compared to Azoxystrobin}

Table 2 depicts the effect of chemical concentration on in vitro inhibition, allowing determination of the minimum inhibitory concentration (MIC) of 3-O-Methylquercetin. The cut-off point used for MIC was $\geq 50 \%$ inhibition of spore germination because in vitro inhibition greater than $50 \%$ is generally repeatable in this test system, while activity less than $50 \%$ is often not repeatable. In all the six pathogens tested, no MICs could be determined at the $50 \%$ inhibition cut-off point for 3-O-Methylquercetin. Azoxystrobin was highly active even at low concentrations against $Z$. tritici and $P$. oryzae fungal pathogens and an MIC would be at a lower concentration. The three Fusarium species exhibited lower sensitivity to azoxystrobin than the other fungi tested with MIC values at least 10 times higher than MICs of the other three fungal species.

\section{DISCUSSION}

3-O-Methylquercetin was isolated and identified for the first time from $L$. glabra Steetz and was found to be in trace $(0.1 \%)$ amounts (42 $\mathrm{mg}$ weight) isolated from $40 \mathrm{~g}$ of dry 


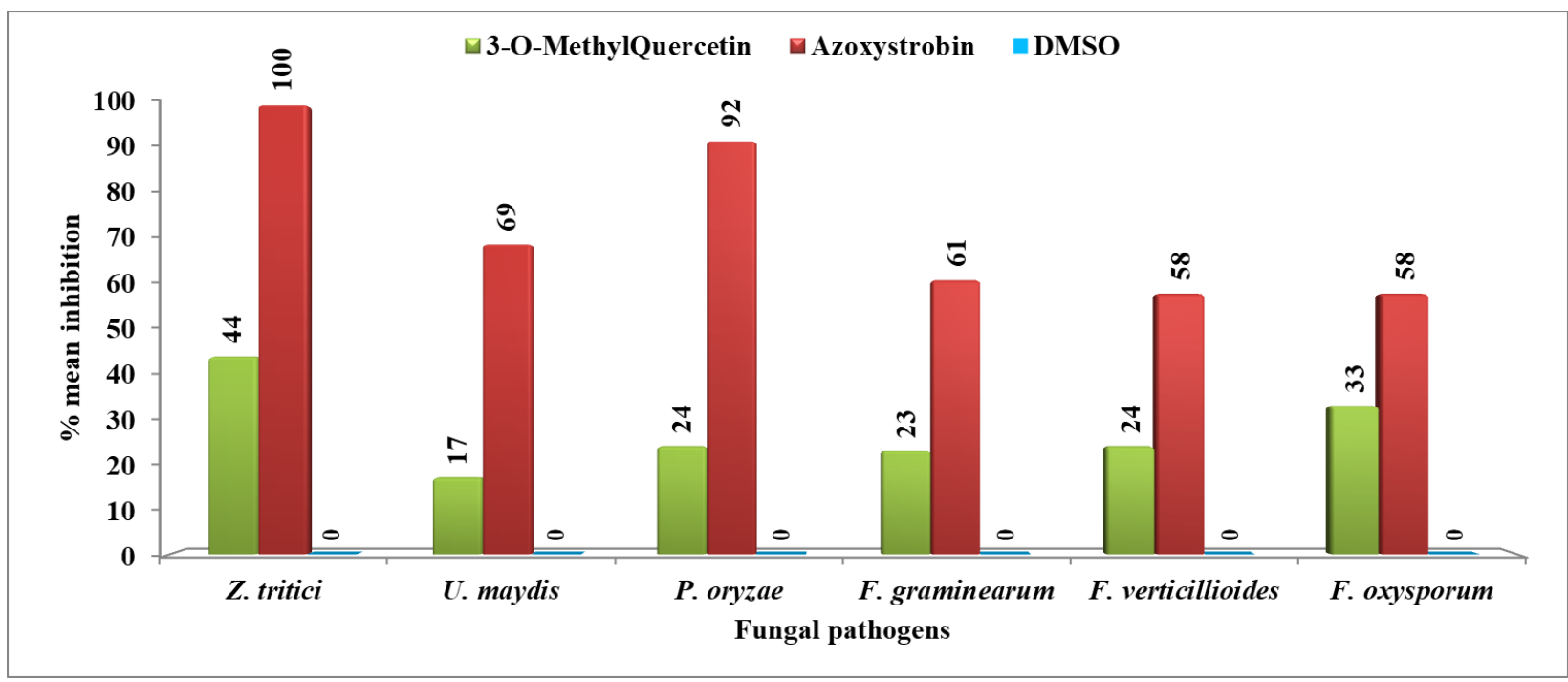

Figure 4. Percentage inhibition of spore germination by $3-O-M e t h y l q u e r c e t i n$ at $27 \mu \mathrm{g} / \mathrm{mL}$ concentration against $Z$. tritici, U. maydis, P. oryzae, F. graminearum, F. verticillioides, and F. oxysporum compared to azoxystrobin at $5 \mu \mathrm{g} / \mathrm{mL}$.

flowers. Hayat et al. (2017) reported that plant flavonoids are generally found in low and variable concentrations, and hence it is challenging to generate their consistent supply. Similar results were reported by Biehl and Ziegleder (2003) who found that some flavonols such as Quercetin, Quercetin-3-glucoside, and Quercetin-3galactoside occurred as minor constituents in cocoa.

Although it has been reported that the flavonol content in plants increases in response to solar radiation, especially ultraviolet-B radiation (Matus, 2016; DelCastillo-Alonso et al., 2016b; Martínez-Lüscher et al., 2014; Berli et al., 2011) and is produced in response to reactive oxygen species (Pollastri and Tattini, 2011), other studies have shown that flavonols may be degraded in high temperatures typical of hot climates (MartinezLüscher et al., 2017; Mori et al., 2007). Severe water stress can also cause flavonol loss in plants (Brillante et al., 2017), leading to changes in the proportion of 3', 4', 5'-OH flavonols. Higher rates of flavonol hydroxylation in response to drought were seen in a red wine grapes study (Martínez-Lüscher et al., 2019) under a hot, dry climate similar to our collection site Machakos County, Kenya (Mohammad et al., 2010; Jaetzold et al., 2006; Jaetzold and Schmidt, 1983).

Flavonoids are shown to inhibit spore germination of plant fungal pathogens (Cushnie and Lamb, 2005). Flavonoid antimicrobial activity depends on their chemical structure (Mierziak et al., 2014), particularly the number, location of functional groups and the degree of structural conjugation (Rice-Evans et al., 1996). 3-OMethylquercetin, which is a flavonol aglycone (flavonol free of sugar moiety), showed a modest antifungal activity of $44 \%$ inhibition of spore germination against $Z$. tritici at the concentration of $27 \mu \mathrm{g} / \mathrm{mL}$ and also exhibited weak antifungal activity against the other five fungal pathogens, $F$. oxysporum, $U$. maydis, $P$. oryzae, $F$. graminearum, and $F$. verticillioides. The antifungal activity of 3-OMethylquercetin might be influenced by free hydroxyl groups at C-5, C-7, C-3', C-4', and a methoxy group at C3 position, which render the molecule polar and enhance the molecule's solubility and interaction with the biological target. This is in agreement with results obtained by Wang et al. (2012) who reported that free hydroxyl groups at C5, C-7, C-3', and C-4' positions or methoxy group at C-3 were essential to antifungal activity of flavonols. However, it was later found that unsubstituted flavonoids showed strong antifungal activity (Mierziak et al., 2014), with hydroxyl and methyl groups in flavones and flavanones reducing their antifungal properties (Weidenborner and Jha, 1993).

The presence of an unsaturated $\alpha-\beta-C 2=C 3$ double bond conjugated with a C-4 carbonyl (a ketone) in ring $\mathrm{C}$ has been associated with a wide spectrum of biological activities, depending on the electronic properties (Amslinger, 2010; Mohammad, 2016). The C-4 carbonyl group of 3-O-Methylquercetin is able to induce electron shifts through resonance effects (withdrawing electrons from the aromatic atoms), therefore influencing continuous dissociation of phenolic hydroxyl groups and methoxy radical stability in ring $B$ (Farmer and Reush, 2019). Unsaturation of $\mathrm{C} 2=\mathrm{C} 3$ double bond in ring $\mathrm{C}$ provides planarity and electron coupling to the molecule (donates electrons to the molecule) so that conjugation between ring $C$ and $A / B$ rings could be obtained (Farmer and Reusch, 2019). Rice-Evans et al. (1996) reported that existence of a $5-\mathrm{OH}$ group in flavonoids provides hydrogen bonding which increases the solubility of the molecule in polar solvents or water and enhances bonding with other 
Table 2. Chemical concentration was a significant factor in determining the minimum inhibitory concentration of 3-O-Methylquercetin compared to azoxystrobin against six test fungal pathogens at $p \leq 0.05$

\begin{tabular}{|c|c|c|c|c|c|c|c|}
\hline \multirow{2}{*}{$\begin{array}{l}\text { Chemical class/or type } \\
\text { of compound }\end{array}$} & \multirow{2}{*}{$\begin{array}{c}\text { CC } \\
(\mu \mathrm{g} / \mathrm{mL})\end{array}$} & \multicolumn{6}{|c|}{ Test-organism/\% inhibition of spore germination } \\
\hline & & $\begin{array}{c}Z . \\
\text { tritici }\end{array}$ & $\begin{array}{c}U . \\
\text { maydis }\end{array}$ & $\begin{array}{c}P . \\
\text { oryzae }\end{array}$ & $\begin{array}{c}F . \\
\text { graminearum }\end{array}$ & $\begin{array}{c}F . \\
\text { oxysporum }\end{array}$ & $\begin{array}{c}\text { F. } \\
\text { verticillioides }\end{array}$ \\
\hline \multirow{9}{*}{ 3-O-Methylquercetin } & 27 & 44 & 17 & 24 & 23 & 33 & 24 \\
\hline & 13.5 & 44 & 9 & 23 & 22 & 32 & 22 \\
\hline & 6.75 & 41 & 6 & 22 & 22 & 30 & 21 \\
\hline & 3.375 & 37 & 4 & 20 & 21 & 23 & 21 \\
\hline & 1.6875 & 35 & 0 & 19 & 20 & 19 & 20 \\
\hline & 0.84375 & 33 & 0 & 14 & 19 & 19 & 14 \\
\hline & 0.421875 & 29 & 0 & 11 & 18 & 18 & 13 \\
\hline & 0.2109375 & 23 & 0 & 0 & 13 & 17 & 10 \\
\hline & MIC & $>27$ & $>27$ & $>27$ & $>27$ & $>27$ & $>27$ \\
\hline \multirow{9}{*}{ Azoxystrobin } & 5 & 100 & 69 & 92 & 61 & 58 & 58 \\
\hline & 2.5 & 97 & 68 & 90 & 54 & 55 & 51 \\
\hline & 1.25 & 96 & 65 & 90 & 46 & 50 & 45 \\
\hline & 0.625 & 96 & 65 & 89 & 35 & 38 & 32 \\
\hline & 0.3125 & 96 & 64 & 89 & 26 & 29 & 20 \\
\hline & 0.156 & 94 & 61 & 87 & 19 & 22 & 16 \\
\hline & 0.078 & 91 & 57 & 81 & 18 & 20 & 13 \\
\hline & 0.039 & 79 & 43 & 76 & 8 & 17 & 10 \\
\hline & MIC & $<0.039$ & 0.078 & $<0.039$ & 2.5 & 1.25 & 2.5 \\
\hline \multirow{8}{*}{ DMSO } & 2 & 0 & 0 & 0 & 0 & 0 & 0 \\
\hline & 2 & 0 & 0 & 0 & 0 & 0 & 0 \\
\hline & 2 & 0 & 0 & 0 & 0 & 0 & 0 \\
\hline & 2 & 0 & 0 & 0 & 0 & 0 & 0 \\
\hline & 2 & 0 & 0 & 0 & 0 & 0 & 0 \\
\hline & 2 & 0 & 0 & 0 & 0 & 0 & 0 \\
\hline & 2 & 0 & 0 & 0 & 0 & 0 & 0 \\
\hline & 2 & 0 & 0 & 0 & 0 & 0 & 0 \\
\hline
\end{tabular}

CC: Chemical concentration $(\mu \mathrm{g} / \mathrm{mL})$ from two-fold serial dilutions; MIC: Minimun inhibitory concentration.

molecules. Therefore, taken together a combination of C4 carbonyl group with unsaturated $\mathrm{C} 2=\mathrm{C} 3$ double bond and any other electron donating group efficiently delocalizes ring $B$ electrons, thus significantly enhancing antifungal activity of 3-O-Methylquercetin across all fungi screened (Rice-Evans et al., 1996).

The lack of sugar moiety (aglycone) may potentiate antifungal activity of 3-O-Methylquercetin in this study. Wang et al. (2012) reported that flavonol aglycones are associated with stronger inhibitory activity on both fungi and bacteria than their corresponding glycones. For instance, 3-O-Methylquercetin exhibited stronger inhibition of Mycosphaerella oryzae spore germination than the corresponding glycones with IC50 values of 35.80 to 67.90 $\mu \mathrm{g} / \mathrm{mL}$.

Sensitivity of test fungi to the isolated 3-O-Methylquer- cetin used in this study significantly varied depending on species. Zymoseptoria tritici was most sensitive of the six fungi followed by Fusarium oxysporum. Pyricularia oryzae, $F$. verticillioides, $F$. graminearun, and Ustilago maydis were less sensitive. All six fungi were highly sensitive to azoxystrobin (a commercialized fungicide). This difference in sensitivity of the fungal pathogens could be explained by the fungi inactivating or excluding 3-O-Methylquercetin or there is a possibility that the compound is unstable or inherently weakly active (Kazan and Gardiner, 2017).

\section{Conclusion}

The pure compound 3-O-Methylquercetin isolated from Linzia glabra Steetz flower extract is a flavonol possessing functional groups such as free hydroxyl groups, $\alpha-\beta$ 
unsaturated $\mathrm{C}=\mathrm{C}$ double bond, conjugated carbonyl group, and a methoxy group. 3-O-Methylquercetin showed modest antifungal activity of $44 \%$ inhibition of spore germination against Zymoseptoria tritici at $27 \mu \mathrm{g} / \mathrm{mL}$ and weaker activity against other five fungi. The standard fungicide, azoxystrobin was consist in its antifungal activity against all six fungi tested. The modest and weak antifungal activities of 3-O-Methylquercetin, an extensively studied flavonoid, exemplify the challenges of natural products research, especially in developing countries. Natural products with useful activity on agricultural pests are exceedingly difficult to find and often require modification to address limitations in practical properties such as UV stability, metabolic stability, compatibility with other active ingredients, appropriate lipophilicityand water solubility. They also may be expensive to isolate in sufficient quantities for wide-scale agricultural use, and may have toxicology issues similar to those of synthetic chemistry. Despite these challenges, natural products have the exciting potential to both provide novel modes of action and to be a local source of valuable pesticides for developing nations. While 3-O-Methylquercetin may not be a useful natural product fungicide for farmers, the search for solutions to the food production challenges of developing countries must continue.

\section{ACKNOWLEDGMENT}

We thank Gandhi Smarak Nidhi fund for partially funding field collection of the plant materials and laboratory consumables. University of Nairobi is highly appreciated for support of the first author to pursue her Ph.D. at the School of Biological Sciences. We are grateful to Corteva Agriscience; fungicide discovery section-as the first author-, for technical support; guidance and mentorship while conducting this research.

\section{CONFLICT OF INTEREST}

The authors declare no conflict of interest.

\section{REFERENCES}

Agati, G., Azzarello, E., Pollastri, S., Tattin, M. (2012). Flavonoids as antioxidants in plants: Location and functional significance. Plant Science, 196, 67-76.

Agnew, A. D. Q., Agnew, S. (1994). Upland Kenya Wild Flowers, 2nd Edition. East Africa Natural History Society, 1994.

Amslinger, S. (2010). The Tunable Functionality of $\alpha, \beta$ Unsaturated Carbonyl Compounds Enables Their Differential Application in Biological Systems. ChemMedChem, 5(3), 351356.

Andreotti, C., Ravaglia, D., Ragaini, A., Costa, G. (2008). Phenolic Compound in Peach (Prunus persica) Cultivars at harvest and during fruit maturation. Annals of Applied Biology, 153(1), 11-23.
Awika, M. J. (2011). Chapter 1: Major cereal grains production and use around the world. ACS Symposium Series; American Chemical Society: Washington, DC.

Bartlett, D. W., Clough, J. M., Godwin, J. R., Hall, A. A., Hamer, M., \& Parr-Dobrzanski, B. (2002). The strobilurin fungicides. Pest Management Science: formerly Pesticide Science, 58(7), 649-662.

Beentje, H. J. (1994). Kenya trees, shrubs and Lianas. National Museums of Kenya, Nairobi.

Berli, F. J., Fanzone, M., Piccoli, P., \& Bottini, R. (2011). Solar UV-B and ABA are involved in phenol metabolism of Vitis vinifera L. increasing biosynthesis of berry skin polyphenols. Journal of Agricultural and Food Chemistry, 59(9), 4874-4884.

Biehl, B., \& Ziegleder, G. (200). Cocoa Chemistry of processing polyphenols, 2nd Edition. Encyclopedia of Food Science and Nutrition, Pp. 1436-1448.

Bouktaib, M., Atmani, A., \& Rolando, C. (2002). Regio-and stereoselective synthesis of the major metabolite of quercetin, quercetin-3-O- $\beta$-D-glucuronide. Tetrahedron Letters, 43(35), 6263-6266.

Brillante, L., Martínez-Luscher, J., Yu, R., Plank, C. M., Sanchez, L., Bates, T. L., Brenneman, C., Oberholster, A., \& Kurtural, S. K. (2017). Assessing spatial variability of grape skin flavonoids at the vineyard scale based on plant water status mapping. Journal of Agricultural and Food Chemistry, 65(26), 5255-5265.

Brown, S. (2012). Comparing More than Two means: OneWayANOVA. www.tc3.edu/instruct/sbrown/stat.

Chadwick, M., Trewin, H., Gawthrop, F., \& Wagstaff, C. (2013). Sesquiterpenoids lactones: benefits to plants and people. International Journal of Molecular Sciences, 14(6), 12780-12805.

Cushnie, T. T., \& Lamb, A. J. (2005). Antimicrobial activity of flavonoids. International Journal of Antimicrobial Agents, 26(5), 343-356.

Del-Castillo-Alonso, M. Á., Diago, M. P., Tomás-Las-Heras, R., Monforte, L., Soriano, G., Martínez-Abaigar, J., \& NúñezOlivera, E. (2016). Effects of ambient solar UV radiation on grapevine leaf physiology and berry phenolic composition along one entire season under Mediterranean field conditions. Plant Physiology and Biochemistry, 109, 374-386.

Farmer, S., \& Reusch, W. (2019). Conjugate aldehyde addition to alpha, beta-unsaturated aldehydes and Ketones. Available at https://chem.libretexts.org/Bookshelves/Organic Chemistry/Supplemental_Modules_(Organic_Chemistry)/Alde hydes_and_Ketones/Reactivity_of_Aldehydes_and_Ketones/ Conjugate_Addition_Reactions.

Ghasemzadeh, A., \& Ghasemzadeh, N. (2011). Flavonoids and phenolic acids: Role and biochemical activity in plants and human. Journal of Medicinal Plants Research, 5(31), 66976703.

Hafiz, A. (1986). Plant diseases Directorate of publication, Pakistan Agricultural Research Council, Islamabad, Pakistan. p. 552.

Hassler, M. (2019). World plants: Synonymic checklists of the vascular plants of the world (version Nov 2018). In: Species 2000 \& ITIS Catalogue of Life, 2019 Annual Checklist (Roskov, Y., Ower, G., Orrell, T., Nicolson, D., Bailly, N., Kirk, P. M., Bourgoin, T., DeWalt, R. E., Decock, W., Nieukerken, E. van, Zarucchi, J., Penev, L., eds.). Digital resource at www.catalogueoflife.org/annual-checklist/2019. Species 2000: Naturalis, Leiden, the Netherlands. ISSN 2405-884X. 
Hayat, M., Abbas, M., Munir, F., Hayat, M. Q., Keyani, R., Amir, R. (2017). Potential of plant flavonoids in pharmaceutics and nutraceutics. Journal of Biomolecules and Biochemistry, 1(1), 12-17.

Herman, P. P. J., \& Swelankomo, N. (2011). Vernonia (Tribe Veronese) and related genera in South Africa: Updates and corrections Bothalia, 41 (1), 176-178.

Hodgson, W. A., \& Grainger, P. N. (1964). Culture of Phytophthora infestans on artificial media prepared from rye seeds. Canadian Journal of Plant Science, 44(6), 583-583.

Hollaway, G. (2014). Septoria Tritici Blotch of Wheat. DEPI Information Note Series May 2014. 2p. Department of Environment and Primary Industries (DEPI), Melbourne, Australia.

Hollman, P. C. H., \& Arts, I. C. W. (2002). Flavonols, flavones and flavonoids- nature, occurrence and dietary burden. Journal of the Science of Food and Agriculture, 80(7), 1081-1093.

Infornet-Biovision. (2011). Maize Smut. Available at http://www.infonet-biovision.org.

Jaetzold, R., \& Schmidt, H. (1983). Farm Management Handbook of Kenya, Vol. II/C. National conditions and farm management information. Part C. East Kenya (Eastern and Cost Provinces). Ministry of Agriculture, Kenya.

Jaetzold, R., Schmidt, H., Hornetz, B., Shisanya, C. (2006). Farm management handbook of Kenya, Vol. II. Natural conditions and farm management information Part C. East Kenya. Nairobi: Ministry of Agriculture, Kenya.

Jaisankar, P., Gajbhiye, R. L., Mahato, S. K., Nandi, D. (2014). Flavonoid Natural Products: Chemistry and Biological Benefits on Human Health: A Review. Asian Journal of Advanced Basic Sciences, 3(1), 164-178.

Ji, Q., Xu, X., \& Wang, K. (2013). Genetic transformation of major cereal crops. International Journal of Developmental Biology, 57(6-7-8), 495-508.

Johns, T., Faubert, G. M., Kokwaro, J. O., Mahunnah, R. L. A., \& Kimanani, E. K. (1995). Anti-giardial activity of gastrointestinal remedies of the Luo of East Africa. Journal of Ethnopharmacology, 46(1), 17-23.

Kazan, K., \& Gardiner, D. M. (2017). Targeting pathogen sterols: Defence and counterdefence? PLoS pathogens, 13(5), e1006297.

Kibet, C. (2011, June). Major challenges facing Kenyan agricultural sector. In International Conference on Innovations in Extension and Advisory Services: Linking Knowledge to Policy and Action for Food and Livelihoods, held in Nairobi, Kenya, November (pp. 15-18).

Kihoro, J., Bosco, N. J., Murage, H., Ateka, E., \& Makihara, D. (2013). Investigating the impact of rice blast disease on the livelihood of the local farmers in greater Mwea region of Kenya. SpringerPlus, 2(1), 308.

Kitonde, C. K., Fidahusein, D. S., Lukhoba, C. W., \& Jumba, M. M. (2013). Antimicrobial activity and phytochemical study of vernonia glabra (steetz) oliv. \& hiern. in Kenya. African Journal of Traditional, Complementary and Alternative Medicines, 10(1), 149-157.

Kolb, C. A., Käser, M. A., Kopecký, J., Zotz, G., Riederer, M., \& Pfündel, E. E. (2001). Effects of natural intensities of visible and ultraviolet radiation on epidermal ultraviolet screening and photosynthesis in grape leaves. Plant physiology, 127(3), 863875.

Kumari, A., Kumar, R., Maurya, S., Choudhary, J. S., \& Kumar, S. (2013). Antifungal efficacy of aqueous extracts of Neem cake, Karanj cake and vermicompost against some phytopathogenic fungi. The Bioscan (Supplement on Medicinal Plants). An International Quarterly Journal of life sciences, 8(2), 671-674.

Martinez-Luscher, J., Brillante, L., \& Kurtural, S. K. (2019). Flavonol profile is a reliable indicator to assess canopy architecture and the exposure of red wine grapes to solar radiation. Frontiers in Plant Science, 10(10), 1-15.

Martinez-Luscher, J., Chen, C. C. L., Brillante, L., \& Kurtural, S. K. (2017). Partial solar radiation exclusion with color shade nets reduces the degradation of organic acids and flavonoids of grape berry (Vitis vinifera L.). Journal of agricultural and food chemistry, 65(49), 10693-10702.

Martínez-Lüscher, J., Sánchez-Díaz, M., Delrot, S., Aguirreolea, J., Pascual, I., \& Gomès, E. (2014). Ultraviolet-B radiation and water deficit interact to alter flavonol and anthocyanin profiles in grapevine berries through transcriptomic regulation. Plant and Cell Physiology, 55(11), 1925-1936.

Matus, J. T. (2016). Transcriptomic and metabolomic networks in the grape berry illustrate that it takes more than flavonoids to fight against ultraviolet radiation. Frontiers in plant science, 7 , 1337.

Mierziak, J., Kostyn, K., \& Kulma, A. (2014). Flavonoids as important molecules of plant interactions with the environment. Molecules, 19(10), 16240-16265.

Mierziak, J., Kostyn, K., \& Kulma, A. (2014). Flavonoids as important molecules of plant interactions with the environment. Molecules, 19(10), 16240-16265.

Mohammad, A. (2016). A review on recent advances and potential pharmacological activities of versatile Chalcone molecule. Chemistry International, 2(1), 1-18.

Mohammad, L., Mwabu, D., Mulwa, R., Mwangi, W., Langyituo, A., La Rovere, R. (2010). Characterization of Maize Producing Household in Machakos and Makueni Districts in Kenya. Country Report-Kenya Nairobi. KARI-CIMMYT.

Mori, K., Goto-Yamamoto, N., Kitayama, M., \& Hashizume, K. (2007). Loss of anthocyanins in red-wine grape under high temperature. Journal of experimental botany, 58(8), 19351945.

Owen, W. J., Sullenberger, M. T., Loso, M. R., Meyer, K. G., \& Slanec, T. J. (2015). Synthesis and antifungal activity of 3-aryl1, 2, 4-triazin-6-one derivatives. Pest Management Science, $71(1), 83-90$.

Owen, W. J., Yao, C., Myung, K., Kemmitt, G., Leader, A., Meyer, K. G., Bowling, A. J., Slanec, T., \& Kramer, V. J. (2017). Biological characterization of fenpicoxamid, a new fungicide with utility in cereals and other crops. Pest management science, 73(10), 2005-2016.

Owuor, B. O., \& Kisangau, D. P. (2006). Kenyan medicinal plants used as antivenin: a comparison of plant usage. Journal of Ethnobiology and Ethnomedicine, 2(1), 7.

Palma-Tenango, M., Soto-Hernández, M., \& Aguirre-Hernández, E. (2017). Flavonoids in Agriculture. Flavonoids: From Biosynthesis to Human Health, 189.

Pataky, J. K., \& Snetselaar, K. M. (2006). Common smut of corn. The Plant Health Instructor. DOI: 10.1094. PHI-I-2006-092701.

Peer, W. A., \& Murphy, A. S. (2007). Flavonoids and auxin transport: modulators or regulators?. Trends in plant science, 12(12), 556-563.

Peter, A. C. (2002). Nonpesticide Methods for Controlling Diseases and Insect Pesticides. Report of the APO Seminar 
on Nonpesticide Methods for Controlling Diseases and Insect pests held in Japan. FAO Bangkok, Thailand.

Pollastri, S., \& Tattini, M. (2011). Flavonols: Old compounds for old roles. Annals of Botany, 108(7):1225-1233.

Ramos, F. A., Takaishi, Y., Shirotori, M., Kawaguchi, Y., Tsuchiya, K., Shibata, H., Higuti, T., Tadokoro, T., \& Takeuchi, M. (2006). Antibacterial and antioxidant activities of quercetin oxidation products from yellow onion (Allium cepa) skin. Journal of Agricultural and Food Chemistry, 54(10), 3551-3557.

Ramsey, A. (2012). What is the most important plant-Pathogenic fungus? https://blog.plantwise.org/2012/04/12/which-is-themost-important-plant-pathogenic-fungus/

Ranum, P., Peña-Rosas, J. P., \& Garcia-Casal, M. N. (2014). Global maize production, utilization, and consumption. Annals of the New York Academy of Sciences, 1312(1), 105-112.

Rice-Evans, C. A., Miller, N. J., \& Paganga, G. (1996). Structureantioxidant activity relationships of flavonoids and phenolic acids, "Free Radical Biology and Medicine, 20(7), 933-956.

Rivera, G., Bocanegra, G., \& Mongec, A. (2010). Traditional plants as source of functional foods. A Review. Journal of Food, 8, 159-167.

Sarker, S. D., Latif , Z., \& Gray, A. I. (2006). Natural product isolation. Methods in Biotechnology, 2nd Edition. Serkar S. D., Latif, Z. I., Gary, A. (eds,). Humana Press, Totowa, New Jersey, Vol. 20, Pp. 1-25.

Solomon, P. S. (2017). New phytologist: Have we finally opened the door to understanding Septoria tritici blotch disease in wheat? Plant Sciences, Research School of Biology. The Australian National University, Canberra, 2601 ACT, Australia.
Song, C., Xiang, D. B., Yan, L., Song, Y., Zhao, G., Wang, Y. H., \& Zhang, B. L. (2016). Changes in seed growth, levels and distribution of flavonoids during tartary buckwheat seed development. Plant Production Science, 19(4), 518-527.

Stenglein, S. A. (2009). Fusarium poae: A Pathogen that Needs More Attention. Journal of Plant Pathology, 91(1), 25-36.

Tazzini, N. (2014). Flavonols: Definition, Structure, Food Sources. https://www.tuscany-diet.net/2014/01/22/flavonoidsdefinition-structure-classification/.

Wamidh, H. T., Musa, H. A. Z., \& Adel, M. M. (2012). Antiproliferative, Antimicrobial and Apoptosis Inducing Effects of Compounds Isolated from Inula viscosa. Molecules, 17 (3), 3291-3303.

Weidenbörner, M., \& Jha, H. C. (1993, September). Antifungal activity of flavonoids in relation to degree of hydroxylation, methoxylation and glycosidation. In International Symposium on Natural Phenols in Plant Resistance 381 (pp. 702-709).

Wink, M. (2010). Introduction: Biochemistry, physiology and ecological functions of secondary metabolites. Annual of Plant Reviews, 40, 1-19.

Ylstra, B., Touraev, A., Moreno, R. M. B., Stöger, E., van Tunen, A. J., Vicente, O., Mol, J. N., \& Heberle-Bors, E. (1992). Flavonols stimulate development, germination, and tube growth of tobacco pollen. Plant physiology, 100(2), 902-907. 